\title{
AGE AS AN EFFECT MODIFIER WITH RESPECT TO GENDER IN ORTHODONTICS IN DEEP BITE PREVALENCE.
}

1. BDS, FCPS

Associate Professor Orthodontics

Nishtar Institute of Dentistry.

2. Ph.D

Associate Professor Statistics Women University Multan.

3. M.Phil

Visiting Lecturer Statistics

Women University Multan.

4. BDS

Postgraduate Resident Orthodontics Nishtar Institute of Dentistry.

5. BDS, MDS

Senior Demonstrator Orthodontics Dental Section, FMU, Faisalabad.

Correspondence Address:

Dr. Zubair Hassan Awaisi

Department of Orthodontics

Nishtar Institute of Dentistry.

zhawaisi76@gmail.com

Article received on:

16/08/2019

Accepted for publication:

07/01/2020

\section{INTRODUCTION}

Deep bite has been considered one of the most common malocclusions and the most difficult to treat successfully. ${ }^{1,2}$ The amount of vertical overlap often varies excessively. ${ }^{3}$ The common definition of overbite was developed by Strang ${ }^{4}$ who defined it as "the overlapping of the maxillary anteriors over mandibular anteriors in the vertical plane." Excessive overbite may be caused by uneven eruption of anteriors, or over-development of anterior alveolus bone. Excessive overbite is commonly seen in patients with a Class II relation. ${ }^{5}$ A study conducted in Aryan and Mongoloid races of Nepal in 2013 showed incidence of deep bites in $34.9 \%$ Aryan and $24.8 \%$ Mongoloid races. ${ }^{6}$

Knowledge about the distribution of different malocclusions may help orthodontic practitioners to better understand the extent of problem in relevant geographic location and would help them in proper orientation and management of the conditions. ${ }^{5,6}$ Hence aim of the present study was to find out the prevalence of deep bite with respect to age and gender in patients visiting Nishtar Institute of Dentistry, Multan.

\section{MATERIAL \& METHODS}

Present cross-sectional study was conducted at orthodontic department of Nishtar Institute of Dentistry, Multan. A total of 200 (126 females, 74 males) having malocclusion in permanent dentition were cross-sectional sampled in this study. The duration of study was 06 months i.e. from 15 December 2018 to 14 June 2019. Patients included in this study were between $7-48$ years having no history of extraction of permanent teeth, and having no grossly decayed teeth. Intra oral examination was done on subjects who visited department of orthodontics in Nishtar Institute of Dentistry Multan. Intra oral examination was carried out with help of mouth mirror and curve probe. Characteristics of deep bite $(>4 \mathrm{~mm})$ were recorded.

\section{RESULTS}

In present study proportion of cases exposed to deep bite are $43 \%$ of the total sample of 200 . In that sample deep bite was observed in $61.1 \%$ in females and $38.4 \%$ in males. It is $97.9 \%$ more likely that the patients presenting with deep bite are males as compared to females. Estimated odds of deep bite in males are $89.2 \%$ higher than 
the estimated odds of female patients with deep bite (Figure-1). The odds of deep bite increases as the age increases in both genders. It is $200 \%$ more likely for the male patients between 21-27 years to present with deep bite than patients with $7-13$ years of age. It is $78 \%$ less likely for female patients between 21-27 years to present with deep bite than patients with 7-13 years of age. Chi square test indicates that there is an association between deep bite and gender. We did not observe deep bites in later ages in 28 years onwards (Table-I).

\section{DISCUSSION}

Deep bite was defined as a condition of excessive overbite, where the vertical measurement between upper and lower teeth is excessive when the mandible is brought into occlusion (Graber, 2011). Hafez ${ }^{7}$ conducted a study on prevalence of deep bite in orthodontic patients in Cairo University in 2014.

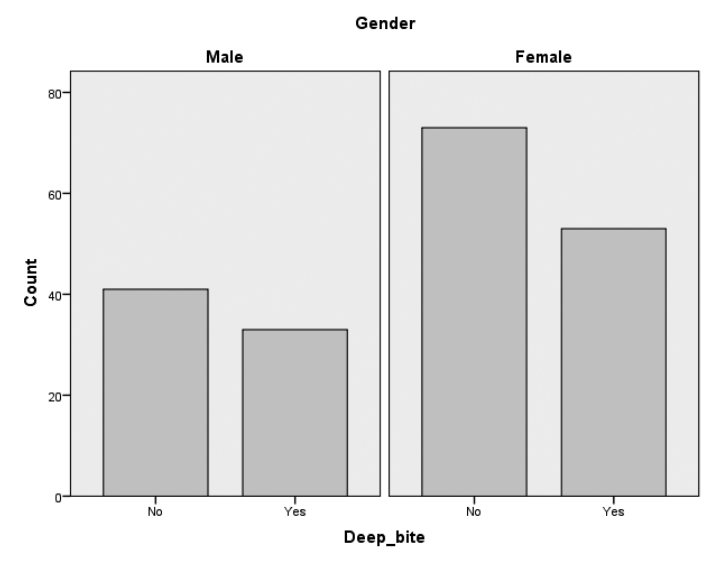

Figure-1. Gender distribution

Out of patients having deep bite, the majority $(80.8 \%)$ had mild deep bite, $15 \%$ had moderate deep bite and $4.2 \%$ had severe deep bite. Higher percentage of males had moderate to severe deepbite, skeletal contributing factors were associated with $15 \%$ of patients with deep bite.

\begin{tabular}{|c|c|c|c|c|c|c|}
\hline \multicolumn{7}{|c|}{ Age Group Deep_bite Gender Cross-tabulation. } \\
\hline \multicolumn{7}{|c|}{ Count } \\
\hline \multicolumn{3}{|c|}{ Gender } & \multicolumn{2}{|c|}{ Deep_Bite } & \multirow{2}{*}{\begin{tabular}{c|} 
Total \\
28
\end{tabular}} & \multirow{2}{*}{$\begin{array}{c}\text { Odds ratio } \\
1.00\end{array}$} \\
\hline \multirow{5}{*}{ Male } & \multirow{4}{*}{ Age Group } & 7 to 13 yrs & 11 & 17 & & \\
\hline & & 14 to 20 yrs & 15 & 20 & 35 & 1.16 \\
\hline & & 28 to 34 yrs & 2 & 0 & 2 & --- \\
\hline & & 42 to 48 yrs & 1 & 1 & 2 & 1.54 \\
\hline & \multicolumn{2}{|l|}{ Total } & 33 & 41 & 74 & \\
\hline \multirow{3}{*}{ Female } & \multirow{2}{*}{ Age Group } & 7 to 13 yrs & 19 & 19 & 38 & 1.00 \\
\hline & & 35 to41 yrs & 0 & 2 & 2 & 0.00 \\
\hline & \multicolumn{2}{|l|}{ Total } & 53 & 73 & 126 & \\
\hline \multirow{6}{*}{ Total } & \multirow{6}{*}{ Age Group } & 7 to 13 yrs & 30 & 36 & 66 & 1.00 \\
\hline & & 14 to 20 yrs & 35 & 57 & 92 & 0.74 \\
\hline & & 21 to 27 yrs & 15 & 17 & 32 & 1.06 \\
\hline & & 28 to 34 yrs & 5 & 1 & 6 & 6.00 \\
\hline & & 35 to 41 yrs & 0 & 2 & 2 & --- \\
\hline & & 42 to 48 yrs & 1 & 1 & 2 & 1.20 \\
\hline
\end{tabular}

Table-II. Gender association with deep bite. 
There was no difference in the prevalence of specific skeletal pattern between males and females with deep over bite. Amin ${ }^{8}$ did a study on prevalence of deep bite in Sulaimani city in Iraq, dental cast of 230 patients were examined. Normal overbite was found in $51 \%$ of the patients and deep bite in $41 \%$ whereas open bite was found in $8 \%$ of the patients. Deep bite was observed in $29.5 \%$ males and $30.5 \%$ females.

Barala ${ }^{9}$ reported prevalence of deep bite in Aryan and mongoloid population. A total of 526 people (260 Mongoloid and 266 Aryan) having malocclusion in permanent dentition were examined. Deep bites in 34.9\% Aryan and 24.8\% Mongoloid was documented. Thailander and Myberg $^{10}$ reported $8.4 \%$ prevalence of deep bite in Swedish school children. Prevalence of deep bite is different in different populations. ${ }^{11-18}$

Within the limitations of this study results showed that there was an insignificant difference in distribution of deep bite in males and females. Emphasis on teaching, research and treatment modalities is suggested in line with these findings.

\section{CONCLUSION}

There was an insignificant difference in distribution of deep bite in males and females. It is observed that with increasing ages deep bite decreases considerably.

Copyright@ 07 Jan, 2020.

\section{REFERENCES}

1. Grieve G. The most difficult problem in orthodontiathe elimination of the deep overbite. Dental Cosmos. 1928; 19:704-7.

2. Mershon JV. Possibilities and limitations in the treatment of closed-bites. International Journal of Orthodontia and Oral Surgery. 1937; 23(6):581-9.

3. Goldstein MS, Stanton FL. Various types of occlusion and amounts of overbite in normal and abnormal occlusion between two and twelve years. International Journal of Orthodontia and Oral Surgery. 1936; 22(6):549-69.

4. RHW S. A textbook of orthodontia. Philadelphia: Lea and Febiger. 1950.
5. Proffit W, Fields 3rd H. Contemporary orthodontics 3rd ed. St Louis: CV Mosby. 2000:185-95.

6. Staley R. Etiology and prevalence of malocclusion In: Bishara SE, editor. Textbook of Orthoodntics. Philadelphia WB Saunders; 2001.

7. Abdulazayem MA. Prevalence and severity of anterior deep bite in a sample of orthodontic patients. CU Theses. 2012.

8. Amin AA, Rashid ZJ. Prevalence of deep bite in orthodontic patients in Sulaimini city-a cross sectional study. IOSR J Dent Med Sci. 2015; 14(8):568.

9. Baral P. Prevalence of malocclusion in permanent dentition in Aryan and Mongoloid races of Nepal-A Comparative study. Pakistan Orthodontic Journal. 2013; 5(2):57-9.

10. Thilander B, Myrberg N. The prevalence of malocclusion in Swedish schoolchildren. European Journal of Oral Sciences. 1973; 81(1):12-20.

11. Ali MS, Azeem M, Akram H, Shakoor U, Mehmood A, Khan MI. Deep bite: Frequency and pattern. Pakistan Oral \& Dental Journal. 2017 Dec 31; 37(4):589-92.

12. HAQ AU, Azeem M, Hussain K, IRFAN S. Correlation between curve of spee and vertical eruption of anterior or posterior teeth in class-II division I malocclusion. Pakistan Oral \& Dental Journal. 2015 Dec 1; 35(4).

13. Azeem M, Tahir A, Ghaffar F. Excessive over bite: Frequency of local dental and skeletal factors. Pakistan Oral \& Dental Journal. 2018 Sep 10; 38(2):2046.

14. Khayat N, Winocur E, Emodi Perelman A, FriedmanRubin P, Gafni Y, Shpack N. The prevalence of posterior crossbite, deep bite, and sleep or awake bruxism in temporomandibular disorder (TMD) patients compared to a non-TMD population: A retrospective study. CRANIO®. 2019 Aug 4:1-7.

15. Dimberg L, Lennartsson B, Arnrup K, Bondemark L. Prevalence and change of malocclusions from primary to early permanent dentition: A longitudinal study. The Angle Orthodontist. 2015 Apr 13; 85(5):72834.

16. Krooks L, Pirttiniemi P, Kanavakis G, Lähdesmäki R. Prevalence of malocclusion traits and orthodontic treatment in a Finnish adult population. Acta odontologica Scandinavica. 2016 Jul 3; 74(5):362-7. 
17. Retna Kumari Narayanan MT, Kumar TA. Prevalence of malocclusion among 10-12-year-old schoolchildren in Kozhikode District, Kerala: An epidemiological study. International journal of clinical pediatric dentistry. 2016 Jan; 9(1):50.
18. Amin AA, Rashid ZJ. Prevalence of deep bite in orthodontic patients in Sulaimini city-a cross sectional study. IOSR J Dent Med Sci. 2015; 14(8):568.

\begin{tabular}{|c|l|l|c|}
\hline \multicolumn{3}{|c}{ AUTHORSHIP AND CONTRIBUTION DECLARATION } \\
\hline Sr. \# & \multicolumn{1}{|c|}{ Author(s) Full Name } & \multicolumn{1}{|c|}{ Contribution to the paper } & Author(s) Signature \\
\hline 1 & Zubair Hassan Awaisi & Supervision of research. & \\
2 & Uzma Khan & Data analysis. & \\
3 & Tooba Nihal & Data review. \\
4 & Iqra Ghaffar & Data collection. \\
5 & Naeem Murtaza & Review critically. & \\
\hline
\end{tabular}

